\title{
Stabilising peat soil with cement and silica fume
}

\begin{abstract}
Stabilising soft, wet and unconsolidated peat soil by using cement as binders and silica fume as additive is often cost-effective compared with other ground improvement methods. This study was carried out by adding $510 \%$ (by weight) cement to peat soil, and silica fume was added at the rate of $5 \mathrm{i} 10 \%$ (by weight) of cement. An air-curing technique was used to cure the samples, as it was found that the water content of the untreated peat soil was very high. The air-cured peat samples were tested for unconfined compressive strength (UCS) and California bearing ratio (CBR) for two conditions: soaked and unsoaked. For the soaked condition the samples were submerged in water for a period of $96 \mathrm{~h}$; the samples after 90 days of air curing were considered as being in the unsoaked condition. From the test results, it was observed that the UCS and CBR increased by a factor as high as 11 and 25 respectively as compared with untreated peat soil. The optimum dose of cement and silica fume was also evaluated. It was observed that the upper layer of in situ peat soil can be stabilised with cement and silica fume to increase the strength of sub-base for the pavement.
\end{abstract}

Keyword: Geotechnical engineering; Pavement design; Strength \& testing of materials 